\title{
Editorial: Systems for Construction Management
}

\author{
Zhen Chen ${ }^{1 *}$ and Heng $\mathrm{Li}^{2}$ \\ ${ }^{1}$ Digital Construction Research Unit, Department of Architecture, University of Strathclyde, Glasgow, United Kingdom, ${ }^{2}$ Smart \\ Construction Laboratory, Department of Buildings and Real Estate, The Hong Kong Polytechnic University, Hong Kong, China
}

Keywords: construction management, management system, system deployment, system design, system development, systems engineering, system modelling, systems thinking

\section{Editorial on the Research Topic}

Systems for Construction Management

\section{BACKGROUND}

The continued advances of management theories and praxis as well as digital technologies have constantly transformed construction project delivery around the world. Practices at many construction project based enterprises show the importance of technical innovations, for which multidisciplinary research and development (R\&D) of systematic solutions is key drivers towards leadership and success. As demonstrated by Ghosh and Robson (2015) in their descriptive case study on project management at the Empire State Building project, the connection from new research to the past practice is powerful to derive and validate the efficacy of the Lean Delivery System, as an example of advanced management system, which is widely recognized essential to produce work process excellence (Patty and Denton, 2010). Under grand challenges (Chen, 2019) in construction management (CM) via continuous enhancement to efficacy and performance, it is important for $\mathrm{R} \& \mathrm{D}$ to be in adaptive, responsive, and/or proactive modes through using state-of-the-art theories and technologies to improve the performance of project-based managerial systems and practices.

The Research Topic on Systems in Construction Management is proposed and coordinated by the two editors from 2018 to 2020 . Figure 1 illustrates its background, goal, and themes. It aims to promote technical advances in the development and use of systems in CM for built environment project, and to showcase new solutions through multidisciplinary practiceoriented R\&D. The call for papers (CfP) was circulated through invitations by emails to experienced academics and posts to LinkedIn groups, and it is open for both experience sharing and rigorous independent research that translate knowledge gained from $\mathrm{R} \& \mathrm{D}$ to inform enhanced practice in CM towards excellent performance target in built environment project delivery.

Received: 25 August 2021 Accepted: 30 September 2021 Published: 31 January 2022

\section{FIVE ARTICLES}

This themed collection consists of five full-length papers, which present professional insights on and novel research into a range of topics relating to systems for construction management. A brief introduction for these published articles is given below. 


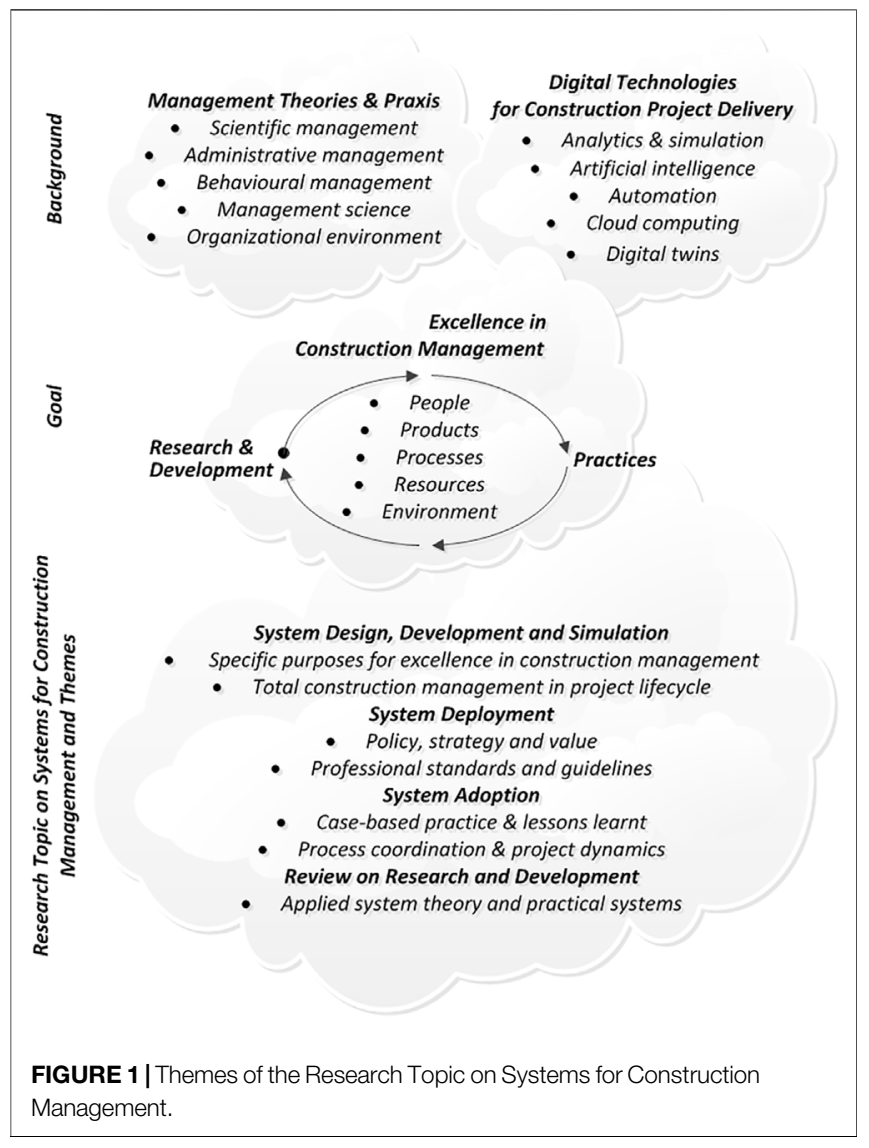

Francis in Canada presents his research into chronographical spatiotemporal scheduling optimization for building projects. This paper describes a hybrid solution based on spatiotemporal techniques to combine graphical, procedural, and algorithmic aspects so as to ensure the continuity in the use of spaces and teams, as well as linear production in construction project management. In the context of this research topic, this article develops the theory of construction scheduling with regard to a systematic integration of multidisciplinary approaches to enhance the plan for construction management.

Larsen et al. in Denmark present their research into mass customization in the house building industry through literature review and discussion. This paper explores existing research into mass customization in the house building industry to identify current knowledge gaps and potential research directions. In the context of this research topic, this article introduces a systemic way to conduct literature review with regard to research and development for industrywide technical enhancement in construction management.

Chen et al. in the United Kingdom and China respectively present a benefits prioritization analysis on adopting BIM systems against major challenges in megaproject delivery. This paper presents a recent research and development experiment on benefits analysis for adopting building information modeling/management (BIM) systems, and it focuses on a new quantitative approach to benefits prioritization to support decision making against major challenges in megaproject delivery. In the context of this research topic, this article describes a systemic approach to evaluate the value of adopting BIM systems in construction management.

Gondo and Miura in Japan present their research into accelerometer-based activity recognition of workers on construction sites. This paper details a method and experimental trials on the use of accelerometer to detect the motion of workers on site with regard to improving productivity or safety. In the context of this research topic, this article describes one of the latest technical advances in the integration of wearable devices such as the accelerometer to inform dada driven construction management system.

Arrotéia et al. in Brazil present their research into barriers to BIM adoption in Brazil. This paper presents a questionnaire-based survey and case study about BIM adoption at one large Brazilian construction company to inform BIM pervasive project delivery. In the context of this research topic, this article describes a specific way of systemic case studies to integrate academic studies and professional practices with regard to best practices to inform further construction management.

\section{AUTHOR CONTRIBUTIONS}

Both authors have made a substantial direct and intellectual contribution to the work, and approved it for publication.

\section{ACKNOWLEDGMENTS}

This research topic has attracted 25,324 views around the world as of 31 July 2021. The two editors of this research topic appreciate the recognition to and interest in this themed issue at Frontiers in Built Environment, and would like to thank all authors who have made great efforts to participate with their valuable manuscripts to support. It is expected that this themed issue is efficacious to support the growth of the Construction Management section at Frontiers in Built Environment, and more academic researchers and professional practitioners will come to share new knowledge.

The two editors of this research topic would like to thank 12 invited academics for their strong supports in the peer review process of this themed issue, and they are:

- Nadia Margaret Anderson, The University of North Carolina at Charlotte, United States;

- Thomas Bock, The Technical University of Munich, Germany;

- Ke Chen, Huazhong University of Science and Technology, China;

- Heap Yih Chong, Curtin University, Australia;

- Laura Florez-Perez, University College London, United Kingdom;

- Youngsoo Jung, Myongji University, South Korea; 
- Marina Marinelli, The University of Leicester, United Kingdom;

- Joaquín Ordieres Meré, The Polytechnic University of Madrid, Spain;

- Chansik Park, Chung-Ang University, South Korea;

- Sergio Scheer, The Federal University of Paraná, Brazil;

- Jolanta Tamošaitiene, Vilnius Gediminas Technical University, Lithuania;

- Jinyue Zhang, Tianjin University, China.

\section{REFERENCES}

Chen, Z. (2019). Grand Challenges in Construction Management. Front. Built Environ. 5, 31. doi:10.3389/fbuil.2019.00031

Ghosh, S., and Robson, K. F. (2015). Analyzing the Empire State Building Project from the Perspective of Lean Delivery System-A Descriptive Case Study. Int. J. Construction Education Res. 11 (4), 257-267. doi:10.1080/15578771.2015.1059395

Patty, R. M., and Denton, M. A. (2010). The End of Project Overruns: Lean and Beyond for Engineering, Procurement and Construction. Irvine, California, USA: Universal Publishers. Chapter 2.

Conflict of Interest: The authors declare that the research was conducted in the absence of any commercial or financial relationships that could be construed as a potential conflict of interest.
Special thanks to two colleagues, including Olli Seppänen at Aalto University in Finland, and Yongkui Li at Tongji University in China, for their strong supports as handling editor in the peer review process when the editors were not available. The Construction Management section of Frontiers in Built Environment has their continuous supports as Associate Editor.

The two editors wish to express appreciation to colleagues at Frontiers for their professional supports in launching this research topic, inviting participates, coordinating peer reviews, and producing publications.

Publisher's Note: All claims expressed in this article are solely those of the authors and do not necessarily represent those of their affiliated organizations, or those of the publisher, the editors and the reviewers. Any product that may be evaluated in this article, or claim that may be made by its manufacturer, is not guaranteed or endorsed by the publisher.

Copyright (c) 2022 Chen and Li. This is an open-access article distributed under the terms of the Creative Commons Attribution License (CC BY). The use, distribution or reproduction in other forums is permitted, provided the original author(s) and the copyright owner(s) are credited and that the original publication in this journal is cited, in accordance with accepted academic practice. No use, distribution or reproduction is permitted which does not comply with these terms. 